The Geneva Papers on Risk and Insurance, 20 (No. 75, April 1995), 141-147

\title{
Emerging Insurance Markets in Far East
}

\author{
by Ben $\mathrm{Ho}^{*}$
}

With the booming economy in countries in the Far East, i.e. Korea, Taiwan, Singapore, Hong Kong, Malaysia, Thailand, Indonesia, the Philippines, China and Vietnam, these territories are naturally seen as the emerging insurance markets in the years to come. Based on the development of these markets in the past ten or twenty years, it may be interesting to draw some observations which may help to see the structural development as well as the problems, risks, opportunities and potential which the industry is going to face in the future.

We do not consider Japan as an emerging market as it is a well-developed insurance market by itself.

\section{Structure of the insurance market}

All insurance markets in the region are basically controlled by local regulatory authorities. Most authorities have the policy to protect the local industries from foreign competition. In addition, they often discourage the out-flow of premium to overseas markets by encouraging the home insurance market to increase the local retention. However, with the GATT agreement in 1994, most countries are now preparing a gradual liberalisation of the insurance market to new foreign insurers.

Some twenty years ago, foreign companies including American and British insurers controlled important markets' shares in Hong Kong, Singapore, Malaysia, Thailand and the Philippines. While these foreign companies have also enjoyed premium growth over the years, their growth has lagged behind the insurance market growth in general as most of the premium growth in the market is taken up by the local insurers. By now, we can easily see that in each market, the top five insurers are normally the domestic companies with local shareholding background. Over the years, the local primary insurers have built up strong local business networks which allow them to take over the market position from

*SCOR Re Asia, Hong Kong. 
the existing foreign insurers. This has also discouraged new foreign insurers from penetrating into a market. It is now very difficult for a new foreign insurer to successfully enter into a market on its own. More often, foreign insurers explore the opportunity by forming joint-venture partners with some local investment. The foreign insurance partner brings in the management and know-how and the local investment brings in the local market colinection.

While "Bancassurance" is very much being discussed in Europe, it is interesting to note that most top local insurers in the Far East are closely linked with the domestic Banks in each country e.g. Thailand, Hong Kong, Malaysia, Singapore and Taiwan. Very often these insurers are being owned, at least partially, by the Banks and the Banks bring in their clients' insurance business to these insurers. In fact, it is generally believed that only those insurers who are affiliated to Banks can have a stable portfolio considering the tense competition in the insurance market.

\section{Physical nature of risks}

With the current booming economic development in the Far East, there are now increasing numbers of large risks in the region. They are capital intensive investments, very often with hundreds of millions US\$ of investment for each project. Some of them are even on a technological level equivalent to the well-developed industrial countries like US and Europe, e.g. the Oil and Gas industries in Korea and Indonesia, and the hi-tech Electronic industry in Taiwan and Korea. In addition, some Asian countries, with a view to elevate rapidly their industrial development, often demand the latest technology, which may not have been fully developed from the foreign investors or suppliers. As a result, the size of operations and the level of technology involved in most of these new risks in the region are now among the most advanced level in the world. These new operations are built up with a technology originated and developed outside the region, e.g. Europe, US and Japan. Despite the assistance of the foreign experience at the management level, the local employees working in these operations, in general, may not be fully aware of the risks associated with the scale of operation and the level of technology involved. They are often behind their counterparts in the technology-exporting countries in terms of experience in operating these new huge operations. In Asia, they have not witnessed the valuable development experience when the technology was gradually upgrading in scale and in level in the technology-exporting countries. Consequently,

- High-technology is transferred but often without the corresponding risk protection that is available in the technology-exporting countries.

- Due to the unawareness of the risks associated, the local operators are unable to acquire the necessary standard of risk prevention concept and loss control planning.

- Due to the size and the level of technology involved, some of the industrial operations in the region are close to a kind of prototype operation. The additional risk exposure associated with these operations is not easily identified by the operators and the overseas technology-exporting suppliers.

- The culture of operation and physical environment in the region can be very different from those in the industrialised countries where the technologies originated. 
- It is very common that the arrangement of insurance coverage is also transferred to the region together with the technology. However, very often the low premium rate and wide insurance coverage copy those in the industrialised countries but the deductibles are not normally maintained at a similarly high level as for the corresponding risks in the industrialised countries. This may be against the interest of the insurance market development in the region.

- In many of the fast developing countries in the region, most of the economic growth has been concentrated in the private sectors. Investments in public infrastructures have been lagging behind the economic development, in general. As a result,

- Public Fire Brigades are not equipped to cope with the peak risks and hi-tech risks in the region.

- Accessibility to fire sites can be difficult due to inadequate roadwork developments.

With the rapid growth in industrial developments, the local authorities in the region may not be able to upgrade the regulatory requirements on hazardous industries, or labour intensive industries particularly in terms of safety, pollution, health and fire protection regulations. While this lagging behind of regulatory controls may have been an element of the lower production cost in the region when comparing with the developed countries, this will cost enormously to the regional economy in future in rectifying the situation, e.g. costs in cleaning up polluted sites, compensations to injured workers, as well as economic and insurance losses in case of a major catastrophe. The major fire events in labour intensive factories killed over a hundred workers in China and Thailand in 1993 and 1994.

\section{The insurance market}

With the rapid growth of economic development, the financial market including the insurance industry in the region is facing a shortage of qualified professionals. The unfavourable public image of the insurers in the region has not helped to attract university graduates to join the insurance industry as a priority career choice. With the drastic changes of technology, legal and social environments in the region, there is a need of reinforcement of engineering, legal and actuarial professionals in the underwriting and management teams in most insurance markets.

The recent growth of insurance markets has been purely the result of the economic growth or increased economic activities in the region. The insurance distribution networks in most markets, through which the insurance products are sold to the insureds are very traditional, normally through insurance agents. There has been little change over the past decade. While most insurance executives share the view that an innovation in insurance marketing is badly needed, for future growth or survival, no major break-throughs are anticipated in this respect in the near future. While the competition among insurers are often said to be on service, price competitiveness is often the main issue in actual practice.

Traditionally, the insured public in the region have not been very claims conscious and insurance has been taken as a kind of "protection". However, coming along with the transfer of technology and with the foreign investments in the region, the new concept of taking insurance as a means of "risk transfer" is gradually introduced to the insured public. This requires underwriters in the region to adjust their underwriting approach. 
Unfortunately, it has not been easy for the regional insurers to respond accordingly to this new change. This partly explains the recent deterioration of the insurance underwriting results in some markets during this transitional period e.g. engineering insurance with an all risks coverage.

The regional insurance market suffers from an inadequate statistical data base in general,

- The drastic change of risk environment, nature and value over the past ten years does not allow underwriters to establish a reliable pricing model. Many new towns or new industrial areas have only been developed in the recent five years, e.g. China.

- Very often, the absence of statistics on losses in an area is simply because there has been virtually no insurance interest there until recently.

- Statistical data on natural hazards, e.g. typhoon, flood and earthquake, are generally not adequate. It should be noted that, in the region, Taiwan, China, Hong Kong, the Philippines, Korea, Vietnam and Indonesia are exposed to one or all of these natural perils.

Unfortunately, the absence of statistical data generally results in a failure to appreciate the risk exposure in terms of the nature and the size of possible losses and hence an underpricing of the insurance. In addition, the need to set up catastrophe reserves is not generally recognised by the insurers in the region. Unlike in Japan where the insurers are fully aware that full earthquake coverage cannot be met by the worldwide insurance capacity, the same attitude is not observed in other markets, e.g. in Taiwan and the Philippines, where full earthquake coverage is readily given by insurers when requested by the insureds.

It is interesting to observe that after years of development, there is still a substantial potential for further growth in the regional insurance market,

- Under-insurance is still a general phenomenon in both the personal line and corporate line of insurance.

- Personal lines are still not fully developed, e.g. house-holder's or house-owner's insurance.

- Casualty lines, e.g. liability business is basically under-developed.

\section{Reinsurance market}

Despite the rapid growth in the region in the past decade, the insurance market is still relatively small at the worldwide level. The local insurance companies are normally less capitalised than the insurance companies in Europe and America. As a result, the retention levels of local insurance companies are generally low and international reinsurers' capacities are generally required. In fire insurance, which is the main class of business requiring reinsurance support, it is not uncommon that half of an insurer's business is reinsured to the international reinsurance market. Unfortunately, due to the size of the market, the reinsurance business volume of many local companies is still at a low level, particularly in Thailand, Indonesia, and Malaysia. 
The markets still heavily rely on proportional reinsurance arrangements in general as there is an over supply of capacity in this respect. Unlike in Europe or America where non-proportional reinsurance arrangements are actively used by insurance companies with a view to increase their retention, non-proportional reinsurance arrangements are only explored in the Far East when there are difficulties in finding reinsurers supporting proportional arrangements, e.g.

- Fire treaties showing continuous losses for consecutive years,

- Motor third party bodily injuries and workman compensation reinsurance.

In the late seventies and early eighties, the reinsurance market in the region was dominated by less than ten professional European Reinsurers, e.g. Munich Re, Swiss Re, SCOR, M \& G, etc. with offices based in Singapore and Hong Kong. By 1994, there were over thirty active European and American reinsurers in the region with around forty representative or branch offices in Singapore, Hong Kong, Taiwan and Kuala Lumpur. In addition, international reinsurers not having offices in the region are now travelling more often than before to the local markets looking for business opportunities.

The local national reinsurers e.g. Korean Re, Central Re Taiwan, Thai Re, Singapore $\mathrm{Re}$, Malaysian National Re, etc are gradually emerging as important players in their respective domestic markets. These regional domestic reinsurers do not maintain a substantial international book of business and they normally do not have a substantial capital base when compared with international reinsurers. A recent survey reveals that the total capital base and premium income of these regional domestic reinsurers in the Far East are just about the same as those of the tenth professional reinsurer in the world. However, the national reinsurers, with the priority cession from the domestic markets, are now reaching the position of the leading reinsurers in their respective domestic markets particularly in the most profitable classes.

The increased presence and marketing activities of reinsurers in the region has resulted in a fierce and, to a certain extent, an unhealthy competition since the late eighties,

- Unbalanced open covers and treaty facilities are given to the local markets. These automatic capacities are not always justified by the low premium income ceded or by the profit margin generated.

- While most treaty programmes are still relatively small, it is a common practice to spread the reinsurance to a wide security panel. As a result, some reinsurers have been suffering from uneconomical participations. This trend is unlikely to change in the near future.

- The over supply of reinsurance capacity has led to a deterioration of profit margin or result to reinsurers particularly on treaty business. Small to medium size insurers can always find a new panel of treaty reinsurers, despite poor results for consecutive years. This delays or prevents the improvement of reinsurance conditions to a reasonable level that is acceptable to reinsurers.

These explain the unfavourable reinsurance result in general in recent years However, it has to be admitted that a large part of the competition in the primary market in the region has been driven by the competition among international reinsurers. 


\section{The future relation between insurers and reinsurers}

Driven by the unsatisfactory performance of reinsurers in Europe and America in the past, the international reinsurance market has been undergoing some significant structural changes since the early nineties,

- Consolidation of reinsurance capacity and concentration of capacity in heavily capitalised reinsurers.

- New business policy and new underwriting approach adopted by international reinsurers.

Traditionally, the reinsurance market in the Far East heavily relies on the support of international reinsurers in London and Europe. The local Far East insurers are now gradually witnessing the impact of the new business policies introduced by the international reinsurance market. Some of the new policies are very different from the traditional philosophy taken by reinsurers in the past. During this transitional period, some great efforts are being made on both sides to reach a common understanding in respect of the future co-operation and relation between insurers and reinsurers,

- In the sixties and seventies, most reinsurers were entering into the market by providing capacity and underwriting and training support to primary insurers in the region. After twenty to thirty years of development, many of the domestic primary insurers have developed successfully their own marketing and technical expertise. While the international reinsurers, at the worldwide group level, are still technically and financially stronger than the individual domestic insurers in the region, the local representative or branch executives of the reinsurers may not be more advanced than the experienced executives in primary domestic insurers, in terms of marketing and underwriting in a particular country, except in the area of large risks underwriting. Nowadays, reinsurers would only commit their support to selected primary insurers who have been able to demonstrate their management skill, sound business policy and good marketing base.

- In the past, the general understanding of reinsurance relation was that any reinsurance deficit to reinsurers would be adjusted and paid back over a number of years. Nowadays, reinsurers are expecting underwriting profits in the first place in order to build up some adequate reserves to pay a major loss which will come in the future.

- The concept of limited capacity, e.g. natural catastrophes and bodily injuries liability are now being introduced by reinsurers.

- Reinsurers are now demanding more "transparency", i.e. information of the business portfolio ceded, from the primary insurers.

- A review and a more realistic common understanding of the underwriting policy of natural hazards in the region, i.e. earthquake, typhoon and flood are being promoted by reinsurers.

- In the past, reinsurance conditions of proportional treaties were adjusted, based on the previous year's performance mainly or purely by increasing or lowering the reinsurance commission. The new approach of "Pricing or Rating of proportional treaties" is now being introduced by the professional reinsurers in the region. This will gradually change the basis of negotiation for proportional treaty reinsurance. 
On the other hand, the primary insurers in the region are having some new expectations from their reinsurers,

- The recent rationalisation of the international reinsurance market has made the primary insurers re-focus on the security of their reinsurers and demand more "transparency" on the quality of the financial background of their reinsurers.

- Additional services are expected from their reinsurers, apart from capacity,

- training,

- international market information,

- new concepts of marketing,

- EDP application,

- New products e.g. casualty business.

The present reinsurance arrangement in the region is unlikely to have a drastic change in the near future, e.g. it is unlikely that the present proportional market of reinsurance in the region will suddenly change to a non-proportional market. While there will be further rationalisation or consolidation of the reinsurance market, the present situation of over supply of reinsurance capacity in the region is not going to improve in the next five years as the domestic primary market is still relatively small at the worldwide level despite the rapid growth in recent years. However, the business relation between primary insurers and reinsurers is undergoing a gradual change nowadays. The recent new business policy of most major reinsurers has led to an intensive discussion in the region. This dialogue among insurers and reinsurers will help to establish the new form of co-operation and business relation between them in responding to the challenges arising from the emerging insurance markets in the region. 